\title{
Validation of Family Management Measure for the Brazilian culture
}

\author{
Validação do Family Management Measure para a cultura brasileira \\ Validación del Family Management Measure para la cultura brasileña
}

\section{Regina Szylit Bousso',III', Carolliny Rossi de Faria Ichikawa', Maira Deguer Misko", Maiara Rodrigues dos Santos', Michelle Freire Baliza'"', Ana Márcia Chiaradia Mendes-Castillo ${ }^{\mathrm{IV}}$, Estela Regina Ferraz Bianchiv}

\author{
'Universidade de São Paulo, Escola de Enfermagem, Postgraduate Program in Nursing. São Paulo, Brazil. \\ "Universidade Federal de São Carlos, Center for Biological and Health Sciences, \\ Department of Nursing. São Carlos, São Paulo, Brazil. \\ "' Universidade de São Paulo, Ribeirão Preto College of Nursing and Nursing School, \\ Inter-Unit Doctorate Program. São Paulo, Brazil. \\ Iv Universidade Estadual de Campinas, Nursing School. Campinas, São Paulo, Brazil. \\ ${ }^{\vee}$ Instituto Dante Pazzanese de Cardiologia, Nursing Division. São Paulo, Brazil.
}

How to cite this article:
Bousso RS, Ichikawa CRF, Misko MD, Santos MR, Baliza MF, Mendes-Castillo AMC, et al.

Validation of Family Management Measure for the Brazilian culture. Rev Bras Enferm [Internet]. 2017;70(6):1151-8.

DOI: http://dx.doi.org/10.1590/0034-7167-2016-0326

Submission: 12-20-2016 Approval: 01-18-2017

\begin{abstract}
Objective: To validate the Family Management Measure (FaMM) for Brazilian culture. Method: Quantitative research excerpt, following the recommendations for validation studies. The data presented refer to the last stage of the process. Results: The internal consistency of the items was analyzed through Cronbach's alpha of the six domains: Child's Daily Life (0.78); Condition Management Effort (0.51); Condition Management Ability (0.55); Family Life Difficulty (0.86); View of Condition Impact (0.56); and Parental Mutuality (0.80). Exploratory factorial analysis of the instrument was carried out, obtaining an acceptable adjustment, according to validation standards. Conclusion: The FaMM presents evidence of validation and can be used in the Brazilian culture under the name of Instrumento de Medida de Manejo Familiar, which was adjusted in eight domains, providing varied aspects of family management and a good evaluation of the fundamental aspects of family life in the context of childhood chronic conditions.
\end{abstract}

Descriptors: Chronic Disease; Family; Child; Validation Studies; Pediatric Nursing.

\section{RESUMO}

Objetivo: Validar o Family Management Measure (FaMM) para a cultura brasileira. Método: Recorte de pesquisa quantitativa, obedecendo às recomendações para estudos de validação. Os dados apresentados referem-se à última etapa do processo. Resultados: Analisou-se a consistência interna dos itens, através do alfa de Cronbach dos seis domínios: Identidade da criança $(0,78)$; Esforço de manejo $(0,51)$; Habilidade de manejo $(0,55)$; Dificuldade da família $(0,86)$; Visão do impacto da doença $(0,56)$; e Mutualidade dos pais $(0,80)$. Realizou-se a análise fatorial exploratória do instrumento, obtendo um ajustamento de acordo com o aceitável para os padrões de validação. Conclusão: O FaMM apresenta evidências de validação, podendo ser utilizado na cultura brasileira com o nome de Instrumento de Medida de Manejo Familiar, o qual foi ajustado em oito domínios, fornecendo aspectos variados do manejo familiar e uma boa avaliação dos aspectos fundamentais da vida familiar no contexto da doença crônica da criança.

Descritores: Doença Crônica; Família; Criança; Estudos de Validação; Enfermagem Pediátrica.

\section{RESUMEN}

Objetivo: Validar el Family Management Measure (FaMM) para la cultura brasileña. Método: Recorte de pesquisa cuantitativa, obedeciendo las recomendaciones para estudios de validación. Los datos presentados se refieren a la última etapa del proceso. Resultados: Se analizó la consistencia interna de los itens, a través del alfa de Cronbach de los seis dominios: Identidad del niño $(0,78)$; Esfuerzo de manejo $(0,51)$; Habilidad de manejo (0,55); Dificultad de la familia $(0,86)$; Visión del impacto de la enfermedad $(0,56)$; y Mutualidad de los padres $(0,80)$. Se realizó el análisis factorial exploratorio del instrumento, obteniendo un ajuste de acuerdo con el aceptable para los padrones de evaluación. Conclusión: El FaMM presenta evidencias de validación, pudiendo ser utilizado en la cultura brasileña con el nombre de 
Instrumento de Medida de Manejo Familiar, lo cual fue ajustado en ocho dominios, proporcionando aspectos variados del manejo familiar y una buena evaluación de los aspectos fundamentales de la vida familiar en el contexto de la enfermedad crónica del niño.

Descriptores: Enfermedad Crónica; Familia; Niño; Estudios de Validación; Enfermería Pediátrica.

\section{CORRESPONDING AUTHOR Regina Szylit BoussoＥ-mail: szylit@usp.br}

\section{INTRODUCTION}

The decline in infant mortality and concomitant increase in chronic diseases in the pediatric age group are unquestionable. In Brazil, the prevalence of chronic disease in children lacks more recent data, but US data indicate that $15 \%$ to $18 \%$ of US children have a chronic condition that causes an interference with health. Among the diseases most associated with these conditions are: sickle cell anemia, bronchopulmonary dysplasia, congenital heart disease, cystic fibrosis, diabetes mellitus, epilepsy and chronic renal failure ${ }^{(1-2)}$.

Such chronic conditions can affect the routine and quality of life of children and families in different ways, which in turn can influence even the prognosis of the disease. Knowing the challenges and ways in which the family handles caring for chronically ill child is a fundamental part of the planning and implementation of quality nursing care and has therefore become a focus of researchers' attention in the last decade ${ }^{(3-5)}$.

It is necessary to maintain a family focus on nursing care because of the importance of the family for survival and especially for caring with the special health needs that the child presents ${ }^{(6)}$.

The term "family management" can be defined as "the role of the family while actively responding to the disease and different health care situations"(7-9). The Family Management Measure (FaMM) is an instrument developed by US researchers to understand how families manage the child's chronic illness and how they incorporate this condition into the family's daily life. This contributes to a more accurate understanding of the factors that support or prevent ideal family functioning for the child(8-10).

The psychometric properties test of the FaMM was based on data from 579 parents of children and adolescents aged 2 to 18 years with chronic conditions, providing strong support for the reliability and validity of the six domains that make up the FaMM ${ }^{(11)}$. This instrument proved to be reliable and applicable in American culture and has been translated for use in countries such as China, Italy, Turkey, Spain, Russia and Thailand. In Australia and Korea the FaMM has already been validated ${ }^{(12-13)}$.

The instrument has been applied in different diagnoses, such as families of children with type 1 diabetes and brain tumor survivors $^{(14-16)}$. It is composed of 53 items and divided into six domains, of which five must be answered by the parent, the child's mother or the person responsible for the child: Child's Daily Life, Condition Management Ability, Condition Management Effort, Family Life Difficulty and View of Condition Impact. The sixth domain, Parental Mutuality, should be applied only to parents or guardians who have adult partners living in the same household.

The domain that addresses the child's daily life has five items about the perception of parents about their children and their daily lives. Higher values reveal a more normal life for the child, despite the illness.
In order to measure condition management ability, the instrument includes twelve items covering the parents' perception about the overall management of the child's state, including knowledge of what needs to be done to care for the disease, the skills and abilities to manage the condition of their children. Higher values mean that the picture is seen as more easily managed.

The condition management effort is evaluated by four items that emphasize the time and work required to manage the situation. Higher values mean greater effort to manage the disease.

In the family life difficulty domain, fourteen items englobe the parents' perception of how having a child with a chronic illness makes family life more difficult. The items in this domain mainly assess family focus and administration of management. Higher values indicate greater difficulty in managing the situation.

To measure the vision of disease impact, the instrument has ten items that address parents' perceptions about the disease severity and its implications for the children and the family's future. Higher values show greater concern in managing the condition.

The parent's mutuality (only for partners living together) is measured by eight items, to address perceptions regarding support, opinion sharing, and satisfaction about how partners work together to manage the child's condition. Higher values indicate normality and greater satisfaction with the way the couple has united to manage this condition.

Despite the existence of a large number of already established instruments to measure family processes in situations of chronic illness, such as communication, decision making, coping and resilience, there are no validated instruments in Brazil aimed at accessing family management in the situation of disease and the incorporation of the disease and treatment regimen into family life ${ }^{(3)}$.

In view of the gap existing in relation to instruments of family management in the context of disease among children and adolescents in our culture, the FaMM was adapted to the Brazilian culture and was denominated Instrumento de Medida de Manejo Familiar. This instrument was applied to 72 relatives of children and adolescents with chronic disease, to evaluate the internal consistency of their psychometric properties, and the pre-test showed that it has applicability in our reality ${ }^{(3)}$.

Therefore, in view of the need to validate the instrument already adapted and aiming to contribute to an understanding of family management of children and adolescents with chronic disease in a Brazilian context, this study aimed to validate the adapted version of the Family Management Measure (FaMM) with families of children and adolescents with chronic disease in Brazilian culture.

\section{METHOD}

\section{Ethical aspects}

The study was approved by the Research Ethics Committee of the University of São Paulo School of Nursing. After clarifying 
the purpose and procedures of the study, the participants signed the Free and Informed Consent Term, according to Resolution $466 / 12^{(17)}$.

\section{Study design, location and period}

This an excerpt of a study that used the quantitative method, following the proposed guidelines for validation of healthrelated measurement instruments ${ }^{(18)}$.

Previously, the cultural adaptation of the Family Management Measure was carried out following the steps: translation into Portuguese, obtaining the first consensus of the translated versions, evaluation by the expert committee, back-translation, pre-test and data treatment ${ }^{(3.19)}$.

The present study performed the validation stage of this adapted instrument, the final stage recommended by the authors for the use of instruments in other cultures, and comprised the application of the instrument to the target population and statistical treatment of the data.

The research was performed in an outpatient care service for chronic diseases of a tertiary university hospital in the city of São Paulo. This service attends on a monthly basis 6,500 children and adolescents of various specialties and, because it is a referral center, receives families of children from different regions of Brazil and neighboring countries with chronic diseases of high complexity. The families were recruited to carry out this study in the units that had granted prior consent to contact the patients' family members, namely: palliative care, nephrology, hematology and oncology outpatient clinics.

It should be noted that the diversity of chronic pathological conditions that the children of this study presented did not interfere in the application, analysis or validation. This approach ensures that the instrument evaluates the family response to the general conditions of the chronic disease, without focusing on a specific condition, only on the active and behavioral ingredient of the management. In addition, the authors recommend using the instrument to compare family management faced with a variety of chronic conditions ${ }^{(11)}$.

The adapted version of the FaMM was applied to participating family members between the months of October 2012 and March 2013.

\section{Sample, exclusion and exclusion criteria}

The study was composed of 262 relatives who accompanied children and adolescents aged 2 to 18 years in outpatient services for chronic diseases in a tertiary university hospital in the city of São Paulo. The sample was determined by convenience and the age of the children/adolescents followed the original research reference ${ }^{(2)}$.

We included family members aged 18 years and over, Brazilians, who resided in the same household as the child, actively participating in the care provided and who agreed to participate in the study. The children and adolescents included in the study have a chronic illness diagnosed for at least six months and have not been hospitalized for at least two months. These criteria were also used by the authors during the construction of the original instrument ${ }^{(11)}$.

The option of applying the instrument to other family members was based on a discussion between the responsible researchers, the committee of specialists for the cultural adaptation of the instrument and the authors of the original instrument. This took into account the fact that in Brazil, many children are cared for by individuals other than family members and their biological mothers and fathers.

\section{Study protocol}

The data were collected through an interview by members of the research group. Before starting data collection, a training day was held with the workers involved in the collection, in order to guarantee uniformity in the process. During this training, the collection sites were presented, guidelines were obtained and questions about the inclusion criteria and method to fill out the instrument were clarified.

During the period of data collection, the researchers stayed on a weekly basis in the outpatient clinics attended by the teams that previously authorized the data collection.

The choice of participants occurred randomly. The interviews were carried out in the waiting room of the outpatient clinic, while the relatives waited for the child's consultation or for the administration of chemotherapy and/or hemoderivatives.

To initiate the contact, the researchers presented themselves to the families with a brief overview of the research, its objectives and inclusion criteria. In the case of eligible participants interested in the study, it was sought to invite the family members to a comfortable and private place when possible. Afterwards, the consent form (FPIC) was read and, upon acceptance and signature, the application of the instrument followed. It should be noted that, due to the physical structure of the institution, there was no private room where relatives could be referred for the application of the instrument, and in many occasions it was applied in a quieter place, but still within the waiting room environment.

A sociodemographic questionnaire on family education, income, diagnosis of the child and time of diagnosis was applied. After the interview, this information was confirmed via the child's medical record.

The application was made alongside the participant, while awaiting the consultation of their child/adolescent. It should be noted that the children/adolescents were not present with the family member who participated in the research. Another family member was asked to stay with the child/adolescent, and when this alternative was not viable, another member of the research group assumed this role, remaining with the child in the recreation room of the outpatient clinic, where cartoons, toys, television were made available as distraction while the family member answered the questionnaire.

The instrument was read by the researchers, in full, to each family member. Each question dealt with was given the time that the participant considered necessary for their answer. When the relative said he/she did not understand the question, no further explanation was given by the researchers; the question was only re-read, up to a maximum of two times. With this, the aim was to interfere as little as possible with the participants' responses. When, after re-reading the questions, the participant still had not yet understood the question, the question was left blank, with a side note explaining what the participant could not understand. Comments and questions raised by survey participants during the application of the 
instrument were also noted in the questionnaires. The mean time of application was 20 minutes.

Responses were recorded according to the Likert Scale, scoring from 1 to 5, meaning from (1) "strongly disagree" to (5) "strongly agree". During the interview, each participant was provided with an answer sheet marked from 1 to 5 , in order to facilitate participants' recall of response options.

The reliability of the instrument was analyzed by the testretest method, with an interval of two to four weeks after the first application of the instrument. This was reapplied for the first 30 study participants.

\section{Results and statistical analysis}

Reliability was analyzed through Cronbach's alpha ${ }^{(20)}$, a coefficient used to evaluate the internal consistency of the items; it shows to what extent all sub-parts of the instrument measure the same characteristic if their indices vary from 0.00 to 1.00 . The higher the reliability coefficient, the more accurate (internally consistent) is the measure ${ }^{(21)}$. For this study, a coefficient of 0.7 was adopted as satisfactory, a measure accepted and considered internationally. Descriptive statistics were used both for characterization of the sample and for the calculation of frequency values, proportions, means, standard deviation and minimum and maximum values. Significance of the tests was set at $5 \%$. The results were obtained with the statistical software R 3.0.1 $1^{(22)}$. For the calculation of the coefficient the Psych package ${ }^{(23)}$ was used. The instrument was subjected to an exploratory factorial analysis with extraction by main axes and oblimin rotation to divide it into domains. The number of factors was chosen by Horn's parallel analysis. Items with a factor loading of less than 0.3 in all factors were eliminated and the others were allocated to the factor whose loading was greater in absolute value. Test-retest reliability was calculated by Pearson's correlation.

\section{RESULTS}

A total of 262 family members of children aged 1 to 17 years with chronic conditions, including mainly biological mothers and fathers $(87.4 \%)$ and $(6.8 \%)$ respectively, followed by grandmothers $(2.6 \%)$, aunts $(1.6 \%)$, stepfathers $(1.0 \%)$ and stepmothers $(0.6 \%)$. Of these, $44 \%$ had completed high school and $12.6 \%$ completed elementary school.

Regarding the income of these families, $57 \%$ considered the family income sufficient, $34.7 \%$ considered their income was insufficient and $8.3 \%$ reported that there was money left at the end of the month. When questioned regarding income before the child's illness, $63.4 \%$ of the family members considered that the family income was sufficient. Among the participants, $85.5 \%$ lived with an intimate partner, with whom they shared responsibility for child care. The diagnoses of the children were varied, covering 89 diagnoses. Of these, the most frequent were Epidermolysis Bullosa (12\%) and Acute Lymphoid Leukemia (6.3\%).

In relation to the statistical analysis of the application of the instrument, Table 1 shows the total scores of each domain of the FaMM.

The highest mean obtained among the domains of the instrument was that of parental mutuality (77.6) and in the internal consistency evaluation the Cronbach's alpha of 0.80 was obtained, with a range of $0-100$. In the condition management effort domain, the mean alpha value of Cronbach 0.51 was obtained for a mean of 76.1, which also occurred in the domains of condition management ability and view of condition impact that had a nonrepresentative alpha value of 0.55 and 0.56 , respectively. The best value of Cronbach's alpha was found in the family life difficulty domain with 0.86 , mean 43.0 and range 0 - 96.4.

Figure 1 shows the z-scores of Cronbach's alpha values of the instrument domains, as well as their representativeness in comparison between domains.

After applying the instrument to the population, a descriptive analysis of the performance of the items of the instrument was performed. Cronbach's alpha, was used to measure the internal reliability of the items of the complete instrument, was equal to 0.89 , and it can be stated that $89 \%$ of the variability of the phenomenon can be explained by this instrument.

Table 1 - Descriptive statistics of the total scores by domains that compose the Family Management Measure, São Paulo, São Paulo State, Brazil, 2013

\begin{tabular}{lcccccc}
\hline Domain & $\mathbf{n}$ & Min & Max & Mean & $\begin{array}{c}\text { Standard } \\
\text { Deviation }\end{array}$ & Cronbach $\alpha$ \\
\hline 1. Child's Daily Life & 262 & 0.0 & 100.0 & 38.7 & 31.5 & 0.78 \\
2. Condition Management Ability & 262 & 3.6 & 100.0 & 61.9 & 17.9 & 0.55 \\
3. Condition Management Effort & 262 & 0.0 & 100.0 & 76.1 & 23.5 & 0.51 \\
4. Family Life Difficulty & 262 & 0.0 & 96.4 & 43.0 & 25.2 & 0.86 \\
5. View of Condition Impact & 262 & 0.0 & 90.6 & 50.9 & 18.6 & 0.56 \\
6. Parental Mutuality & 224 & 0.0 & 100.0 & 77.6 & 23.5 & 0.80 \\
\hline
\end{tabular}

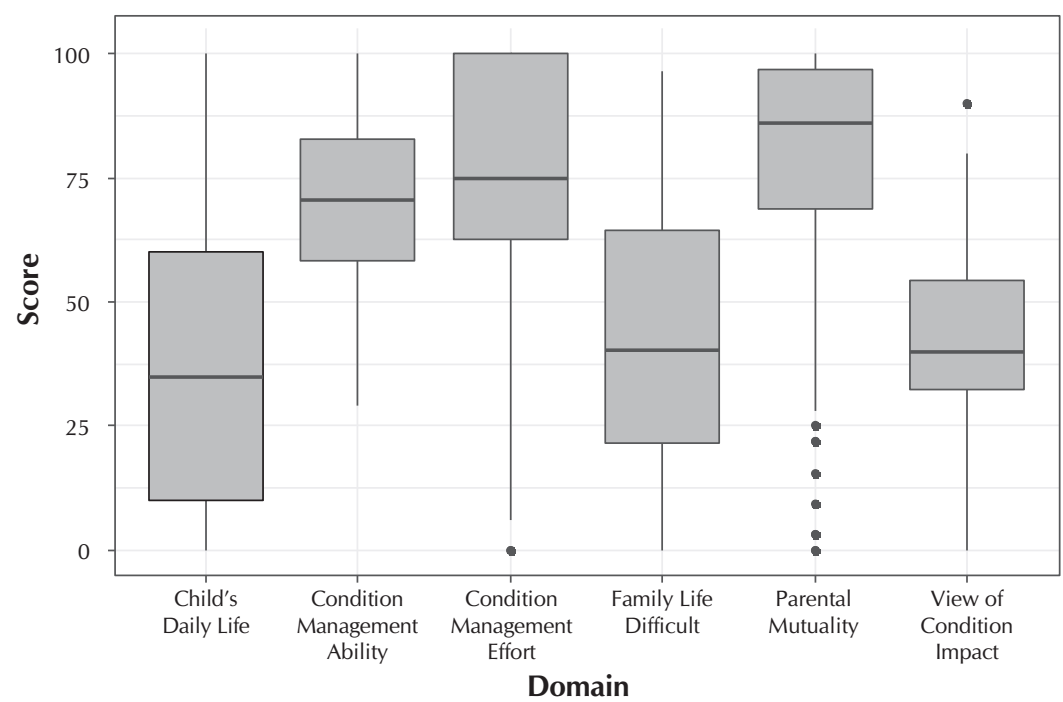

Figure 1 - Boxplot for the distribution of domains 
The individual characterization of each item demonstrated that the exclusion of items with low internal reliability value would not improve the Cronbach's alpha value in the domains, thereby not justifying the exclusion of any item. The item-factor correlation of all items was low. The same is true for the domains Condition Management Ability, Condition Management Effort and View of Condition Impact; however, these values were adjusted after factorial analysis of the instrument.

In order to evaluate the reliability of the instrument, the testretest was also performed. The instrument was reapplied to 30 relatives after 2 to 4 weeks of the first application, obtaining a value of 0.33 to 0.67 , showing evidence of reliability.

The exploratory factorial analysis of the items of the instrument was performed for the validation of the construct and were adjusted in 8 domains, as shown in Table 2:

Table 2 - Distribution of instrument factor weights, São Paulo, Brazil, 2015

\begin{tabular}{|c|c|c|c|c|c|c|c|c|c|}
\hline & Item & PA1 & PA2 & PA5 & PA3 & PA4 & PA8 & PA6 & PA7 \\
\hline Q2 & 2 & 0.709 & & & & & & & \\
\hline Q43 & 43 & 0.574 & & & & & & & \\
\hline Q9 & 9 & 0.567 & & & & & & & \\
\hline Q38 & 38 & -0.555 & & & & & & & \\
\hline Q6 & 6 & 0.505 & & & & & & & \\
\hline Q45 & 45 & 0.471 & & & & & & & \\
\hline Q22 & 22 & 0.468 & & & & & & & \\
\hline Q36 & 36 & 0.431 & & & & 0.318 & & & \\
\hline Q31 & 31 & 0.406 & & & & & 0.366 & & \\
\hline Q23 & 23 & -0.365 & & & & & & & \\
\hline Q34 & 34 & & & & & & & & \\
\hline Q42 & 42 & & & & & & & & \\
\hline Q48 & 48 & & 0.868 & & & & & & \\
\hline Q53 & 53 & & 0.806 & & & & & & \\
\hline Q50 & 50 & & 0.753 & & & & & & \\
\hline Q51 & 51 & & 0.655 & & & & & & \\
\hline Q52 & 52 & & -0.603 & & & & & & \\
\hline Q47 & 47 & & -0.399 & & & & & & \\
\hline Q46 & 46 & & 0.389 & & & & & & \\
\hline Q16 & 16 & & & 0.574 & & & & & \\
\hline Q39 & 39 & & & 0.521 & & & & & \\
\hline Q29 & 29 & & & 0.502 & & & & & \\
\hline Q1 & 1 & & & -0.489 & & & & & \\
\hline Q20 & 20 & & & 0.471 & & & & & \\
\hline Q5 & 5 & & & 0.446 & & & & & \\
\hline Q10 & 10 & & & -0.423 & & & & & \\
\hline Q33 & 33 & & & 0.365 & & & & & \\
\hline Q37 & 37 & & & 0.358 & & & & & \\
\hline Q26 & 26 & & & -0.321 & 0.314 & & & & \\
\hline
\end{tabular}

To be continued
Table 2 (concluded)

\begin{tabular}{|c|c|c|c|c|c|c|c|c|c|}
\hline & Item & PA1 & PA2 & PA5 & PA3 & PA4 & PA8 & PA6 & PA7 \\
\hline Q4 & 4 & & & & 0.51 & & & & \\
\hline Q14 & 14 & & & -0.307 & 0.465 & & & & \\
\hline Q40 & 40 & & & & 0.449 & & & & \\
\hline Q18 & 18 & & & & 0.437 & & & & \\
\hline Q44 & 44 & & & & 0.306 & & & & \\
\hline Q21 & 21 & & & & & & & & \\
\hline Q28 & 28 & & & & & 0.616 & & & \\
\hline Q27 & 27 & & & & & 0.529 & & & \\
\hline Q17 & 17 & & & & & & & & \\
\hline Q19 & 19 & & & & & & & & \\
\hline Q30 & 30 & & & & & & 0.617 & & \\
\hline Q35 & 35 & & & & & & 0.487 & & \\
\hline Q11 & 11 & & & & & & & & \\
\hline Q8 & 8 & & & & & & & & \\
\hline Q12 & 12 & & & & & & & -0.454 & \\
\hline Q3 & 3 & & & & & & & 0.381 & \\
\hline Q24 & 24 & & & & & & & 0.351 & \\
\hline Q25 & 25 & & & & & & & -0.333 & \\
\hline Q15 & 15 & & & & & & & -0.32 & \\
\hline Q7 & 7 & & & & & & & & \\
\hline Q32 & 32 & & & & & & & & \\
\hline Q13 & 13 & & & & & & & & 0.488 \\
\hline Q49 & 49 & & & & & & & & 0.433 \\
\hline Q41 & 41 & & & & & & & & 0.306 \\
\hline
\end{tabular}

\section{DISCUSSION}

The objective of this study was to report the validation process of the FaMM, step after the cultural adaptation meticulously performed and already documented in the national literature ${ }^{(3)}$.

The FaMM proposes to evaluate family management in the context of childhood chronic conditions. Through a recent and extensive bibliographical review, it was verified that this study is the first to report the use of scales to evaluate the family management construct in the Brazilian culture.

Evidence shows that health indicators that cannot be measured directly, such as behavior, beliefs, attitudes and motivations, are challenges for translating and validating instruments in other cultures ${ }^{(24-25)}$. However, although advances have been made in research in this area, there are few approaches to adaptation and cross-cultural validation of instruments to measure health behavior.

Nevertheless, methodologically, it is considered more appropriate to adapt scales than to develop new ones for the same construct ${ }^{(25)}$. The process of adaptation and validation of existing instruments, rather than the elaboration of a new one, has considerable advantages. When adapting an instrument, the researcher is able to compare data obtained in different samples, from various contexts, allowing greater equity 
in the evaluation, since it is the same measure that evaluates a subjective construct from the same theoretical and methodological perspective. It is understood that the use of adapted and validated instruments allows for greater capacity for generalization and also the investigation of differences between a growing diversified population ${ }^{(26)}$.

The validity of an instrument can be obtained in three levels of evidence: validity of content, construct and criterion. Validity of content refers to the degree to which an instrument reflects a specific content domain; Construct validity refers to how the measurement is internally related in a coherent and reliable way; Criterion validity refers to the degree to which the instrument compared to other external criteria measures the same concept ${ }^{(27)}$.

The validation of FaMM content was done by comparing translations and back translations, as well as by consensus of the peer committee during cultural adaptation ${ }^{(3)}$.

The internal consistency analysis of the instrument was performed by obtaining Cronbach's alpha, which is considered to probably be the most important step from the scientific point of view. The alpha measures the degree of covariance of a series of items and ranges from 0 to 1 ; the higher the count, the greater the reliability of the instrument. A value of at least 0.7 reflects acceptable reliability. Reliability of an instrument refers to the degree to which an instrument produces consistent and coherent results from its scores.

The internal consistency value conferred by Cronbach's alpha (0.89) was close to the value obtained in the original instrument $(0.72 \text { to } 0.91)^{(11)}$. For the correlation coefficients between the test and retest measures applied to 30 family members with a range of 2 to 4 , obtained reliability of $(0.33$ to 0.67$)$, a value that was lower than that found by the authors of the original instrument for the test-retest $(0.71 \text { to } 0.94)^{(11)}$.

In relation to the six domains of the instrument, three domains reached values less than expected: Condition Management Effort (0.53); Condition Management Ability (0.57); and View of Condition Impact (0.54). On the other hand, the domains Child's Daily Life (0.77), Family Life Difficulty (0.86) and Parental Mutuality (0.82) had reliability values considered to be acceptable.

Authors point out that items with high correlation index and Cronbach's alpha have more variance and contribute more to the reliability of a scale than items with low values. Therefore, items with unsatisfactory scores should be considered for exclusion from the scale ${ }^{(19)}$.

In the exploratory factorial analysis of the main components of the instrument, the variables of the factor components indicate that the variance of these variables is reproduced by common factors. After analysis of the results obtained (selection of items with factorial weight higher than 0.3), it was verified that these do not diverge from the original version, maintaining the composition of the scale. The correlational analysis between the items of the scale and the global scale concludes that the instrument measures the family management of children with chronic conditions, since it shows that the correlations between all items and the global scale are stronger than the correlations only between items.

Although the three domains that make up the original instrument (Condition Management Effort, Condition Management
Ability and View of Condition Impact) did not present a high reliability index, in the tests for validation these domains showed good adjustment, making the validation process acceptable.

The reliability and validity of an instrument in another culture is a challenge, considering that in the case of family management of children with chronic illness, for example, it is not only the instrument itself that should be evaluated, but the cultural equivalence of the concept that is being measured ${ }^{(24)}$. Even within a single culture, ethnic differences, in dialect and language, gender, family constitution, age and education interfere in the measures that are proposed to access certain behavior of individuals in the disease context ${ }^{(28)}$.

It is well known that the literal translation of a scale is not sufficient in validation processes. The greatest challenge is often to adapt it in a way that renders it relevant, feasible and understandable to the desired culture, while still maintaining the meaning and intent of the original items ${ }^{(25)}$.

Therefore, at the conclusion of an instrument validation process, it is important to reflect on cultural obstacles that may hamper the process of adapting the new version of an instrument, such as, for example, the conceptual evaluation of the items by the target population and its applicability in the culture investigated. Furthermore, discussion is necessary with the author of the original instrument regarding adjustments and modifications proposed in the new version of the instrument ${ }^{(29)}$.

For the validity of the instrument construct, it was submitted to an exploratory factorial analysis, where the six domains proposed in the original instrument were adjusted into eight domains, allowing a good evaluation of the fundamental aspects of family life in the context of the chronic illness of the child, thereby providing varied aspects of family management.

Based on the theoretical model underlying the one-dimensional structure tested, it showed a good quality of adjustment the $\mathrm{TLI}=0.8728$ and the RMSEA $=0.0403 ;(\mathrm{Cl} 90 \%=0.03)$. The TLI needs to be close to 0.90 , while the recommended RMSEA is up to $0.08^{(30)}$.

The instrument name adopted in the Brazilian version sought to meet the denomination of the original scale. In relation to the application of the instrument, some changes were chosen, with the knowledge and agreement of the authors of the original instrument. While these authors applied the FaMM by telephone in Brazil, this option was impracticable due to the difficulty of Brazilians adhering to this type of research and even the difficulty of accessing the telephone data of these families. Faced with this, it was decided to apply the instrument in person with as little interference as possible on the part of the researchers. The researchers also developed a rule demonstrating the response options from "strongly disagree" to "agree", to facilitate participants' responses, since the Likert-type scale was considered by participants to be difficult to answer.

\section{Study limitations}

Application of the instrument was performed in the waiting room of an outpatient clinic, faced with many external stimuli, which may have made it difficult to understand. Still in relation to their applicability, the participants considered the instrument long and difficult to understand; sometimes it was 
necessary to repeat questions, but the items were not repeated more than twice so as not to interfere with the uniformity of the instrument's application.

It was not possible to carry out the criterion validation due to the scarcity of instruments that measure the variable studied. To complete the process it is recommended to compare its psychometric properties with other validated instruments with similar measures ${ }^{(18)}$. Therefore, the lack of instruments in the Brazilian culture with psychometric properties similar to the FaMM made the validation process difficult, consequently it is a limitation of this study. Given the lack of studies with similar measures, one possibility of future research in order to obtain criterion validation is to follow the families over time and to verify whether the FaMM is able to predict family adjustment after the recovery period of the child.

In addition, considering that the retest rate was low, the authors of the original instrument indicated the continuity of the research, in order to increase the number of retest participants and refining some aspects according to the above mentioned difficulties.

\section{Contribution to Health sector}

Through the use of the instrument it is possible to understand how families deal with stressful situations in their daily life, how they face the demands caused by the disease and what kind of resources these families have access to. The use of this instrument in the evaluation of family management can help health professionals in the planning of interventions specific to each family.

\section{CONCLUSION}

Although the three domains that make up the original instrument (Condition Management Effort, Condition Management Ability and View of Condition Impact) did not present a high reliability index, in the tests used for the validation they obtained a good adjustment, thereby indicating that the validation process was acceptable.

Thus, the eight domains adjusted in this instrument presented indexes of validity, and as such the Family Management Measure Instrument is recommended for use in Brazilian culture. These domains provide an insight into a variety of aspects of family management and can provide a good assessment of the fundamental characteristics of family life in the context of a child's chronic illness.

\section{FINANCIAL SUPPORT}

This work received a financial grant from Fundação de Amparo à Pesquisa do Estado de São Paulo (FAPESP). Project Fapesp 2010/15404-1, São Paulo, SP, Brazil.

\section{REFERENCES}

1. Jacob CMA, Silva CAA, Ribeiro JD. O impacto das doenças crônicas no paciente pediátrico [Internet]. Hospital das Clínicas: Faculdade de Medicina da USP. Instituto da Criança. 2015 [cited 2015 Jul 30]. Available from: http://icr.usp.br/subportais/raiz/ projeto/projeto_4.pdf

2. Knafl KA, Deatrick JA, Knafl GJ, Gallo AM, Grey M, Dixon J. Patterns of family management of childhood chronic conditions and their relationship to child and family functioning. J Pediatr Nurs [Internet]. 2013[cited 2014 Nov 04];28(6):523-35. Available from: http://www.ncbi.nlm.nih.gov/pmc/articles/PMC4316683/pdf/nihms659817.pdf

3. Ichikawa CRF, Bousso RS, Misko MD, Mendes-Castillo AM, Bianchi ERF, Damião EBC. Cultural adaptation of the Family Management Measure among families of children and adolescents with chronic diseases. Rev Latino-Am Enfermagem [Internet]. 2014[cited 2015 Mar 22];22(1):115-22. Available from: http://www.scielo.br/pdf/rlae/v22n1/0104-1169-rlae-22-01-00115.pdf

4. Bousso RS, Misko MD, Mendes-Castillo AM, Rossato LM. Family Management Style Framework and its use with families who have a child undergoing palliative care at home. J Fam Nurs [Internet]. 2012[cited 2014 Jun 10];18(1):91-122. Available from: http://jfn.sagepub.com/content/18/1/91.full.pdf

5. Mendes-Castillo AM, Bousso RS, Ichikawa CRF, Silva LR. The use of the Family Management Style Framework to evaluate the family management of liver transplantation in adolescence. Rev Esc Enferm USP [Internet]. 2014[cited 2015 Sep 1];48(3):430-7. Available from: http://www.scielo.br/pdf/reeusp/v48n3/0080-6234-reeusp-48-03-430.pdf

6. Cabral IE, Moraes JRMM. Family caregivers articulating the social network of a child with special health care needs. Rev Bras Enferm [Internet]. 2015[cited 2016 Jan 11];68(6):1078-85. Available from: http://www.scielo.br/pdf/reben/v68n6/en_0034-7167reben-68-06-1078.pdf

7. Knafl KA, Deatrick JA. Family Management Style: concept analysis and development. J Pediatr Nurs [Internet]. 1990 [cited 2015 Nov 2];5(1):4-14. Available from: http://www.pediatricnursing.org/article/0882-5963(90)90047-D/pdf

8. Knafl KA, Deatrick JA. Family Management Style and the challenge of moving from conceptualization to measurement. J Pediatr Oncol Nurs [Internet]. 2006[cited 2014 Feb 4];23(1):12-8. Available from: http://jpo.sagepub.com/content/23/1/12.full.pdf

9. Knafl KA, Deatrick JA, Havill NL. Continued development of the Family Management Style framework. J Fam Nurs [Internet]. 2012 [cited 2014 Mar 20];18(1):11-34. Available from: http://jfn.sagepub.com/content/18/1/11.full.pdf

10. Knafl KA, Deatrick JA. Further refinement of the Family Management Style Framework. J Fam Nurs [Internet]. 2003 [cited 2015 Jul 11];9(3):232-56. Available from: http://jfn.sagepub.com/content/9/3/232.full.pdf 
11. Knafl K, Deatrick JA, Gallo A, Dixon J, Grey M, Knafl G, O’Malley J. Assessment of the psychometric properties of the Family Management Measure. J Pediatr Psychol [Internet]. 2011 [cited 2014 May 18];36(5):494-505. Available from: http://www.ncbi. nlm.nih.gov/pmc/articles/PMC3131701/pdf/jsp034.pdf

12. Kim DH, Im YJ. Validity and reliability of Korean version of the Family Management Measure (Korean FaMM) for families with children having chronic illness. J Korean Acad Nurs [Internet]. 2013 [cited 2015 Dec 3];43(1):123-32. Available from: http:// synapse.koreamed.org/Synapse/Data/PDFData/0006JKAN/jkan-43-123.pdf

13. Hutton A, Munt R, Aylmer C, Deatrick JA. Using the Family Management Measure in Australia. Neonatal Paediatr Child Health Nurs [Internet]. 2012 [cited 2015 Sep 4];15(2):17-27. Available from: http://www.academia.edu/23852685/ Using_the_family_management_measure_in_Australia

14. Deatrick JA, Mullaney EK, Mooney-Doyle K. Exploring family management of childhood brain tumor survivors. J Pediatr Oncol Nurs [Internet]. 2009 [cited 2014 Jan 9];26(5):303-11. Available from: http://www.ncbi.nlm.nih.gov/pmc/articles/PMC2846323/ pdf/nihms-187726.pdf

15. Rearick EM, Sullivan-Bollyai S, Bova C, Knafl KA. Parents of children newly diagnosed with type 1 diabetes: experiences with social support and family management. Diabetes Educ [Internet]. 2011 [cited 2015 Nov 11];37(4):508-18. Available from: http:// tde.sagepub.com/content/37/4/508.full.pdf

16. Kim DH, Im YJ. The influence of Family Management Style on psychosocial problems of childhood cancer survivors in Korea. Eur J Oncol Nurs [Internet]. 2015 [cited 2016 Feb 15];19(2):107-12. Available from: https://www.ncbi.nlm.nih.gov/pubmed/25466826

17. Brasil. Ministério da Saúde; Conselho Nacional de Saúde. Resolução n. 466, de 12 de dezembro de 2012. Dispõe sobre as diretrizes e normas regulamentadoras de pesquisas envolvendo seres humanos [Internet]. MS: Brasília; 2012 [cited 2014 Apr 1]. Available from: http://conselho.saude.gov.br/resolucoes/2012/Reso466.pdf

18. Knafl GJ, Grey M. Factor analysis model evaluation through likelihood cross-validation. Stat Methods Med Res [Internet]. 2007 [cited 2015 Nov 4];16(2):77-102. Available from: http://www.ncbi.nlm.nih.gov/pmc/articles/PMC2984549/pdf/nihms21195.pdf

19. Guillemin F, Bombardier C, Beaton D. Cross-cultural adaptation of health-related quality of life measures: literature review and proposed guidelines. J Clin Epidemiol [Internet]. 1993 [cited 2014 Jun 10];46(12):1417-32. Available from: http://www.jclinepi. com/article/0895-4356(93)90142-N/pdf

20. Cronbach LJ. Coefficient alpha and the internal structure of tests. Psychometrika [Internet]. 1951 [cited 2015 Dec 15];16(3):297334. Available from: http://link.springer.com/article/10.1007/BF02310555

21. Polit DF, Beck CT. Fundamentos de Pesquisa em Enfermagem. Avaliação de evidências para a prática de enfermagem. $7^{\mathrm{a}}$ ed. Porto Alegre: Artmed; 2011.

22. R Core Team. R: A language and environment for statistical computing[Internet]. Vienna (Austria): R Foundation for Statistical Computing; 2016 [cited 2016 Jul 1]. Available from: https://cran.r-project.org/doc/manuals/r-release/fullrefman.pdf

23. Revelle W. psych: Procedures for Personality and Psychological Research. R package version 1.5.8. [Internet]. Evanston (USA): Northwestern University. 2015 [cited 2016 Apr 1]. Available from: http://personality-project.org/r/psych-manual.pdf

24. Vreeman RC, McHenry MS, Nyandiko WM. Adapting health behavior measurement tools for cross-cultural use. J Integr Psychol Ther [Internet]. 2013 [cited 2015 Nov 4];1(2):1-6. Available from: http://www.hoajonline.com/journals/pdf/2054-4723-1-2.pdf

25. Sperber AD. Translation and validation of study instruments for cross-cultural research. Gastroenterology [Internet]. 2004 [cited 2014 Jul 15];126(1 Suppl 1):S124-8. Available from: http://www.gastrojournal.org/article/S0016-5085(03)01564-6/pdf

26. Lee SY, Lee EE. Cross-cultural validation of instruments measuring health beliefs about colorectal cancer screening among Korean Americans. J Korean Acad Nurs [Internet]. 2015 [cited 2016 Jan 30];45(1):129-38. Available from: http://synapse.koreamed.org/ Synapse/Data/PDFData/0006JKAN/jkan-45-129.pdf

27. Puggina AC, Silva MJP. Interpersonal Communication Competence Scale: Brazilian translation, validation and cultural adaptation. Acta Paul Enferm [Internet]. 2014 [cited 2015 Jun 11];27(2):108-14. Available from: http://www.scielo.br/pdf/ape/v27n2/en_01032100-ape-27-02-0108.pdf

28. Gonzalez JM, Rubin M, Fredrick MM, Velligan DI. A qualitative assessment of cross-cultural adaptation of intermediate measures for schizophrenia in multisite international studies. Psychiatry Res [Internet]. 2013 [cited 2014 Dec 11];206(2-3):166-72. Available from: http://www.ncbi.nlm.nih.gov/pmc/articles/PMC3615112/pdf/nihms419423.pdf

29. Borsa JC, Damásio BF, Bandeira DR. Cross-cultural adaptation and validation of psychological instruments: some considerations. Paidéia[Internet]. 2012 [cited 2014 Jul 10];22(53):423-32. Available from: http://www.scielo.br/pdf/paideia/v22n53/en_14.pdf

30. Kline RB. Principles and practice of structural equation modeling. 3th ed. New York: Guilford Press. 2011. 